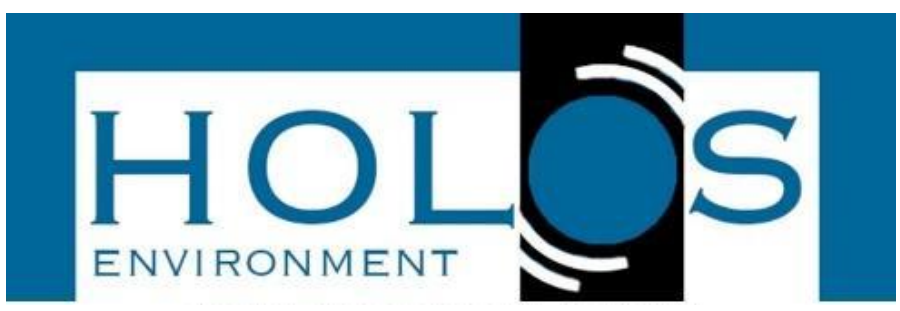

\title{
UTILIZAÇÃO DE ÁCIDOS ORGÂNICOS COMO ALTERNATIVA PARA HIGIENIZAÇÃO DE ALIMENTOS: UMA REVISÃO INTEGRATIVA
}

\section{UTILIZATION OF ORGANIC ACIDS AS AN ALTERNATIVE FOR FOOD HYGIENIZATION: AN INTEGRATING REVIEW}

\author{
Ramilly Rodrigues Cavalcante ${ }^{1}$; Renata Carmo de Assis ${ }^{1}$
}

Artigo recebido em: 23/03/2020 e aceito para publicação em: 24/04/2020.

DOI: http:/dx.doi.org/10.14295/holos.v20i3.12381

\begin{abstract}
Resumo: Os alimentos apresentam em sua composição uma microbiota natural. O grande impasse está em impedir a colonização natural por esta microbiota. Os ácidos orgânicos são constituintes naturais de muitos alimentos e são amplamente utilizados como aditivos conservantes devido sua atividade antimicrobiana. A metodologia consistiu em uma revisão integrativa buscando estudos relatando a utilização dos ácidos orgânicos como agente sanitizante de alimentos. Ao final da pesquisa obtiveram-se 10 artigos que foram analisados e discutidos de acordo com cada ácido orgânico. A depender de sua natureza, concentração e tempo de tratamento, os ácidos orgânicos possuem uma potencial aplicação como sanitizantes para alimentos.
\end{abstract}

Palavras-chave: Higienização. Ácidos orgânicos. Desinfecção. Hortaliças. Microorganismos.

\begin{abstract}
The food presents in its composition a natural microbiota. The great impasse is in preventing natural colonization by this microbiota. Organic acids are natural constituents of many foods and are widely used as preservative additives because of their antimicrobial activity. The methodology consisted of an integrative review seeking studies reporting the use of organic acids as a food sanitizing agent. At the end of the research 10 articles were obtained and analyzed according to each organic acid. Depending on their nature, concentration and treatment time, organic acids have a potential application as food sanitizers.
\end{abstract}

Keywords: Hygiene. Organic acids. Disinfection. Vegetables. Microorganisms.

\section{INTRODUÇÃO}

Os alimentos, independentemente de sua origem, apresentam em sua composição uma microbiota natural, advinda do tecido original do mesmo. $O$ consumo de vegetais prontos está ganhando certa popularidade no mercado, mas a manutenção da segurança microbiana desses produtos requer uma abordagem sistêmica que englobe todos os aspectos de produção, processamento, distribuição e uso (CASTRO-IBÁÑEZ; ALLENDE, 2017). O grande impasse está em impedir a colonização natural por esta microbiota, além

\footnotetext{
${ }^{1}$ Universidade Estadual do Ceará (UECE), Fortaleza, CE. E-mail: (ramilly rrc@hotmail.com, renata carmo assis@hotmail.com)
} 
da contaminação por outros microrganismos durante o processamento, no caso de alimentos de origem vegetal, desde a colheita, transporte, manipulação e consumo pelo indivíduo (YAMAGAUCHI et al., 2013).

Os produtos frescos tem grande potencial para abrigar patógenos, sendo um veículo de Doenças Transmitidas por Alimentos (DTAs). As diversas e complexas fontes e rotas de patógenos entéricos para frutas e vegetais têm sido amplamente pesquisadas, dentre elas a interação do uso da terra, gestão da água, padrões climáticos e propriedades e fontes específicas de patógenos. (ALEGBELEYE et al., 2018)

Dessa forma, existem procedimentos operacionais específicos e direcionados ao controle higiênico-sanitário do alimento localizados na RDC № 275/2002 e 216/2004 da ANVISA (Agência Nacional de Vigilância Sanitária), Portaria № 368/1997 e Instrução Normativa № 1/2000 do MAPA (Ministério da Agricultura Pecuária e Abastecimento) (RODRIGUES; RIBEIRO, 2015).

Segundo dados epidemiológicos, as Unidades Produtoras de Refeições (UPRs) são um dos locais onde ocorrem surtos de doenças com origem alimentar e os causadores desses danos à saúde destacam-se os agentes físicos, agentes químicos e agentes microbiológicos. Onde as complicações decorrentes vêm aumentando gradativamente, sendo responsáveis por um alto número de hospitalizações e em alguns casos com consequências irreversíveis ao paciente (ABRANCHES, 2015).

Indivíduos expostos aos agentes correm graves riscos, pois as DTAs podem ocasionar altas taxas de mortalidade. Os fatores determinantes variam desde a ingestão de um alimento de má qualidade contendo agentes infecciosos ou toxinas, à quantidade do alimento contaminado ingerido e ao estado imunológico do indivíduo acometido (MEDEIROS et al., 2013).

Métodos de desinfecção atuais são capazes de reduzir as populações microbianas naturais na superfície dos produtos e estudos mostram que a desinfecção de vegetais em diferentes tratamentos (cloro, ácido cítrico, luz ultravioleta e ozônio) são influenciados pela dose do agente, pelo tempo de exposição e superfície do produto alimentar (BERMÚDEZAGUIRRE; BARBOSA-CÁNOVAS, 2013; OLMEZ; KRETZSCHMAR, 2009)

Portanto, os erros mais frequentes na manipulação dos alimentos evidenciados incluem: o preparo dos alimentos com muita antecedência, a má higienização dos alimentos que serão consumidos crus, o cozimento inadequado, o armazenamento e/ou o reaquecimento das refeições de forma inadequada, a contaminação cruzada de 
microorganismos e toxinas, bem como a ausência de higiene pessoal dos manipuladores (MEDEIROS et al., 2013).

A contaminação das frutas e hortaliças pode ocorrer por meio da utilização de água de irrigação ou adubos inadequados nas hortas, no transporte, nos pontos de venda e na higienização incorreta do alimento (TAKANAYAGUI et al., 2001).

O hipoclorito de sódio é um composto com muita procura pela população mundial devido à sua eficácia ao nível da desinfecção comumente empregado para frutas, vegetais e hortaliças. Uma vez que este produto demonstra elevada capacidade sanitizante a um custo relativamente baixo. No entanto devido a sua instabilidade e reatividade, facilmente perde as propriedades que o tornam comercialmente atrativo e eficaz (PINTO, 2014).

Meireles et al. (2016) em um estudo de revisão demonstra fortes preocupações ambientais e de saúde pública com o uso de cloro como desinfetante, pois este composto químico é considerado poluente devido à sua capacidade de formar mutagênicos e carcinogênicos compostos ao reagir com matéria orgânica. Várias novas estratégias surgem como alternativas mais ecológicas baseadas em uso de compostos biológicos.

Além disso a variação da concentração desse produto durante o tratamento de hortifrutis pode comprometer a saúde do consumidor, devido à presença de derivados clorados nesses compostos, como os trihalometanos, que são substâncias carcinogênicas (COELHO et al., 2015).

A disponibilização de tecnologia que utilize substâncias alternativas ao uso de produtos clorados para a higienização de alimentos pode representar opção de interesse para o mercado. Para isso, seu uso deve manter as características físicas, químicas e sensoriais do alimento atrativas ao consumidor, além de serem seguras e eficientes em termos microbiológicos (FERNANDES, 2013).

Os ácidos orgânicos são constituintes naturais de muitos alimentos e são amplamente utilizados como aditivos conservantes devido sua atividade antimicrobiana. Esta propriedade atribuída aos ácidos orgânicos deve-se à sua ação sobre o pH do alimento, que gera aumento da concentração de prótons no meio e sua difusão nas células microbianas. Com isso, ocorre redução do pH celular, alterações de permeabilidade de membranas, transporte de nutrientes e inibição de enzimas (JOSÉ, 2017).

A valorização econômica de resíduos e subprodutos como os ácidos orgânicos, apesar de relevante, não é facilmente sustentável economicamente. Embora contemple uma matéria-prima de baixo custo, implica um elevado custo de logística, armazenamento e transporte, bem como a utilização de processamentos com elevado consumo energético. 
Nesse sentido, as evidencias para que haja essa valorização econômica, têm mostrado que é fundamental o processamento de quantidades elevadas de matéria-prima (PINTADO; TEIXEIRA, 2015).

Alguns exemplos de ácidos orgânicos têm sido investigados e analisados como agentes antimicrobianos naturais e bastante considerados na categoria de aditivos conservantes como os ácidos lático, cítrico e acético. Estes têm sido descritos como fortes agentes atuando sobre a inativação de microrganismos mesófilos e psicrotróficos em frutas e hortaliças (JOSÉ, 2017).

A pesquisa tem como objetivo realizar um levantamento bibliográfico sobre o uso de ácidos orgânicos no mundo para higienização de alimentos consumidos crus e a partir disso difundir sobre a existência de métodos de higienização de alimentos com esse tipo específico de agente, além de fazer comparativos com os métodos já conhecidos pela população, discutindo sobre a eficácia ou não da ação sanitizante promovida pelos ácidos orgânicos sobre alimentos frescos ou minimamente processados.

\section{MATERIAL E MÉTODOS}

Como preconiza a metodologia de revisão integrativa de literatura, foram sumarizadas pesquisas anteriores para a partir delas obter conclusões gerais e assim analisar o conhecimento científico sobre o assunto a ser investigado. A realização desta pesquisa seguiu as seguintes etapas básicas: 1) elaborar o tema do estudo; 2) realizar a pesquisa bibliográfica; 3 ) organizar os dados coletados; 4) interpretar e avaliar os resultados do estudo; 5) apresentar e divulgar a revisão (MENDES et al., 2008).

$\mathrm{Na} 1^{\text {a }}$ etapa partiu-se de uma problemática norteadora envolvendo o risco de intoxicação alimentar e transmissão de doenças advindas do consumo de alimentos higienizados incorretamente, especificamente alimentos frescos ou minimamente processados, pois geralmente estes são consumidos crus. Com isso, o que os estudos prévios apresentam de evidências sobre diferentes métodos de higienização de alimentos? Os ácidos orgânicos são eficazes em sua ação antimicrobiana e antiparasitária quando utilizados na higienização de alimentos, especificamente, in natura ou minimamente processados?

A $2^{\text {a }}$ etapa, foi dado início ao levantamento bibliográfico, com a utilização de artigos científicos sobre Ácidos orgânicos e Qualidade e Segurança higiênico-sanitária de 
alimentos, especificamente àqueles consumidos in natura ou minimamente processados, cujos dados serviram para corroborar as informações teóricas presentes nesta revisão.

Os termos de busca utilizados nesta revisão foram obtidos através de consulta aos Descritores em Ciências da Saúde. Foi utilizada na busca dos trabalhos algumas combinações dos descritores em inglês "organic acids, lactic acid, acetic acid, citric acid, desinfection, vegetables, fruit, quality control e noxae".

Foram selecionados artigos originais e comunicações breves, disponibilizados pelo Portal de Periódicos da Coordenação de Aperfeiçoamento de Pessoal de Nível Superior, CAPES, no Brasil/Brazil. Foram critérios de inclusão publicações no período de 1996 a 2018, tendo sido periódicos impressos ou indexados, com a presença de resumos (em português, inglês ou espanhol) contendo a descrição da abordagem sobre uso e/ou ação e/ou atividade de ácidos orgânicos na higienização de alimentos e/ou hortaliças.

Foram excluídos os estudos que não apresentavam em seus resumos foco em atividade sanitizante de alimentos frescos ou minimamente processados (como estudos envolvendo animais ou produtos incomestíveis, por exemplo), resumos de eventos, relatos de caso, editoriais, revisões sistemáticas, meta-análises e artigos de opinião.

Fez-se uma leitura exploratória dos títulos e resumos dos artigos. Depois, fez-se uma leitura mais aprofundada dos artigos na íntegra. A partir desta leitura, foram excluídas as pesquisas irrelevantes ao tema do estudo. Em seguida, já com a amostra final determinada, realizou-se a leitura analítica, cuja finalidade foi ordenar e sumarizar as informações contidas nos artigos selecionados para responder aos objetivos da pesquisa.

A $3^{\mathrm{a}}$ etapa consistiu na elaboração de um esquema para a coleta de dados a fim de esquematizar todo o processo de busca, visualizando quantos estudos foram incluídos ou excluídos.

$\mathrm{Na} 4^{\mathrm{a}}$ etapa foi formulada uma tabela a fim de anotar as informações consideradas mais relevantes para atender aos objetivos desta pesquisa. A tabela contém dados como autor, ano de publicação, país onde o estudo foi desenvolvido, tipo de amostra utilizada no experimento e principais considerações de cada estudo.

Na $5^{\text {a }}$ etapa as informações de cada estudo que se apresentaram mais relevantes à revisão foram expostas de modo descritivo. Os dados foram organizados sucinta e individualmente para facilitar a análise crítica da amostra e as conclusões prévias obtidas a partir de cada leitura. 


\section{RESULTADOS E DISCUSSÃO}

A escolha dos artigos se deu a partir de uma busca em 2 bases de dados diferentes: Periódicos CAPES, Plataforma Digital Unicamp (SBU) e localizados a partir de listas de referências. Na plataforma Periódicos Capes foram encontrados 658 artigos, na Plataforma Digital Unicamp (SBU) 26 artigos e localizados a partir de listas de referências foram 4 artigos.

Do total de artigos selecionados 195 artigos estavam em duplicidade de revisão, capítulos de livro ou fora do objetivo do estudo. 493 artigos foram selecionados após leitura dos títulos e resumos, dos quais 483 artigos não atenderam ao critério de seleção. Após a aplicação dos critérios de exclusão e inclusão resultou-se em 10 artigos selecionados para a revisão.

$\mathrm{Na}$ Tabela 01 é apresentada uma visão geral dos estudos selecionados a partir da pesquisa, evidenciando seu autor principal, o ano de publicação, o país em que foi realizado, o agente sanitizante, a amostra que foi higienizada no experimento e por fim, as principais considerações do autor sobre o estudo.

Em alguns trabalhos houve a necessidade da leitura completa do arquivo, pois só assim seria possível o entendimento do assunto abordado pelo autor. Dessa forma, as pesquisas foram sendo classificadas individualmente após avaliação detalhada como aptas ou inaptas para inclusão. Nesta tabela as pesquisas estão dispostas em ordem cronológica de forma a acompanhar a evolução dos estudos e metodologias utilizados.

Vale salientar que a maioria dos trabalhos envolvem não só a utilização de ácidos orgânicos como método alternativo de higienização de alimentos, mas também de outras formas de higienização como ozonização ou através de ultrassom. Entretanto, apenas as considerações mais importantes referentes aos ácidos orgânicos utilizados como agentes sanitizantes nos experimentos foram evidenciadas na tabela.

Os estudos são artigos publicados em revistas de diversas nacionalidades, o que exige a necessidade de busca avançada dos locais onde realmente foram realizados. Entretanto houve certa dificuldade de encontrar esta informação. Optou-se por identificar o local daqueles que não especificassem essa informação como "Não Informado". Por fim, uma observação importante relacionada ao percentual de estudos encontrados no Brasil foi identificada, pois das pesquisas utilizadas nesta revisão, $20 \%$ foram realizadas no país. Isso indica forte interesse dos pesquisadores brasileiros em encontrar produtos alternativos para higienização de alimentos frescos ou minimamente processados. 
Notou-se ainda que a alface é a hortaliça mais utilizada neste tipo de experimento, dado que $50 \%$ dos estudos selecionados a utilizou como instrumento de amostra. Isso atrela-se ao fato de ser um alimento de fácil acesso, bastante comum em qualquer região, susceptíveis à contaminação e alta taxa de alterações organolépticas devido ao uso de agentes químicos durante a sanitização (CAVALCANTE et al., 2014).

\section{1 Ácido Acético ou Ácido Etanóico $\left(\mathrm{CH}_{3} \mathrm{COOH}\right)$}

O primeiro estudo discutido que evidencia a ação do ácido acético como agente sanitizante de vegetais e hortaliças é também o estudo mais antigo contido nesta revisão, realizado por Zhang e Farber (1996). Neste trabalho avaliou-se a eficácia de diferentes desinfetantes contra Listeria monocytogenes em alface e repolho minimamente processados. As hortaliças foram compradas, cortadas à mão, divididas em porções de $100 \mathrm{~g}$ e armazenadas em sacos plásticos. Após esse momento inoculou-se $0.5 \mathrm{~mL}$ de solução pré-preparada com cultura da bactéria. Em seguida deu-se início à etapa de sanitização.

No que diz respeito aos ácidos orgânicos, nesse estudo foram utilizados diferentes concentrações $(0.5,0.75$ e $1 \%)$, tanto isolados ou combinados com 100ppm de cloro, a fim de enriquecer os resultados e todos os tratamentos foram feitos por $10 \mathrm{~min}$. Em relação ao ácido acético isolado, observou-se sua ação agindo com menor eficácia em relação ao cloro isolado, pois tendo como referência a atividade deste último, que em 10min a 200ppm reduziu 10 logs da bactéria, a atividade do ácido acético a $1 \%$ de solução por $10 \mathrm{~min}$, pôde reduzir apenas 2.5logs da bactéria.

Os demais resultados com este ácido não obtiveram diferenças significativas e o autor supõe que as diferenças de $\mathrm{pH}$ influenciaram tais resultados. Alguns anos mais tarde desenvolveu-se um estudo sobre a ação do ácido acético contra Escherichia Coli e Salmoella Typhimurium inoculadas em alfaces frescas. O método utilizado por Chang e Fang (2007) neste estudo consistiu primeiramente em imergir amostras de $25 \mathrm{~g}$ da hortaliça lavada com água destilada em solução pré-preparada com culturas das bactérias mencionadas. Depois foram submetidas à tratamento com vinagre de arroz diluído em água destilada formando assim soluções a $0.05,0.5$ e $5 \%$ de ácido acético. 
Tabela 01 - Dados referentes aos autores, ano de publicação, país onde o estudo foi desenvolvido, amostra utilizada nos experimentos e as principais considerações do estudo

\begin{tabular}{|c|c|c|c|c|c|}
\hline Referência & Ano & País & Sanitizante & Amostra Utilizada & Considerações do Autor \\
\hline Zhang e Farber & 1996 & $\begin{array}{c}\text { Não } \\
\text { informado }\end{array}$ & $\begin{array}{l}\text { Ácido lático e } \\
\text { Ácido acético }\end{array}$ & Alface e Repolho & $\begin{array}{l}\text { O ácido lático provou ser mais eficaz } \\
\text { que o ácido acético na redução do } \\
\text { número de } L \text {. monocytogenes. Foram } \\
\text { observadas reduções máximas de } 0,5 \\
\text { e } 0,2 \text { logs após } 10 \text { min de exposição } \\
\text { em soluções a } 1 \% \text { de cada ácido } \\
\text { orgânico. }\end{array}$ \\
\hline Chang e Fang & 2007 & Taiwan & Ácido acético & Alface & $\begin{array}{l}\text { O vinagre de arroz comercial }(5 \% \text { de } \\
\text { ácido acético) reduziu } 3 \text { logs de } \\
\text { população de } E \text {. em alface a } 25^{\circ} \mathrm{C} \text { em } \\
5 \text { min de tratamento. }\end{array}$ \\
\hline Akbas e Ölmez & 2007 & Turquia & $\begin{array}{l}\text { Ácido lático, } \\
\text { ácido acético e } \\
\text { ácido cítrico }\end{array}$ & Alface & $\begin{array}{l}\text { A imersão de alface em ácido cítrico a } \\
0,5 \% \text { ou em solução de ácido lático a } \\
0,5 \% \text { por } 2 \text { min pode ser tão eficaz } \\
\text { quanto o cloro na redução de } \\
\text { populações microbianas em alface } \\
\text { americana recém cortada. }\end{array}$ \\
\hline Martínez-téllez et al. & 2009 & México & Ácido lático & Aspargos e cebolas & $\begin{array}{l}\text { O desinfetante mais efetivo avaliado } \\
\text { para desinfestação de aspargos } \\
\text { frescos e cebolinha verde foi o ácido } \\
\text { lático a } 2 \% \text {, seguido do cloro a } \\
250 \text { ppm. }\end{array}$ \\
\hline Park, et al. & 2011 & $\begin{array}{l}\text { Coreia do } \\
\text { Sul }\end{array}$ & $\begin{array}{l}\text { Ácido } \\
\text { propanoico, } \\
\text { acético, lático, } \\
\text { málico e cítrico }\end{array}$ & $\begin{array}{c}\text { Maçã vermelha e } \\
\text { alface }\end{array}$ & $\begin{array}{l}\text { Sugere-se que os ácidos orgânicos } \\
\text { tenham uma aplicação potencial como } \\
\text { sanitizantes para produtos orgânicos } \\
\text { frescos. }\end{array}$ \\
\hline
\end{tabular}


Tabela 01 - Dados referentes aos autores, ano de publicação, país onde o estudo foi desenvolvido, amostra utilizada nos experimentos e as principais considerações de estudo

\begin{tabular}{|c|c|c|c|c|c|}
\hline Referência & Ano & País & Sanitizante & Amostra Utilizada & Considerações Do Autor \\
\hline Massey et al. & 2013 & EUA & $\begin{array}{l}\text { Ácido málico e } \\
\text { Ácido lático }\end{array}$ & Melão & $\begin{array}{l}\text { O tratamento com os ácidos orgânicos } \\
\text { málico e lático descritos na pesquisa } \\
\text { evidenciaram sua eficácia na utilização } \\
\text { como desinfetantes alternativos aos } \\
\text { comerciais. }\end{array}$ \\
\hline Nascimento e Alencar & 2014 & Brasil & Ácido acético & $\begin{array}{l}\text { Alface, coentro, } \\
\text { repolho e couve }\end{array}$ & $\begin{array}{l}\text { De acordo com o tipo de agente } \\
\text { sanitizante, constatou-se que a solução } \\
\text { de hipoclorito de sódio a } 1 \% \text { e a solução } \\
\text { de ácido acético a } 6,6 \% \text { apresentaram } \\
\text { ação antiparasitária similares com } \\
p \leq 0,001 \text { e } p \leq 0,004 \text {, respectivamente. }\end{array}$ \\
\hline Akbas e Cag & 2016 & Turquia & $\begin{array}{l}\text { Ácido cítrico, } \\
\text { ácido málico e } \\
\text { ácido gálico }\end{array}$ & $\begin{array}{c}\text { Biofilmes de Bacillus } \\
\text { subtilis }\end{array}$ & $\begin{array}{l}\text { Os efeitos do ácido cítrico foram tão } \\
\text { poderosos quanto os tratamentos com } \\
\text { cloro. }\end{array}$ \\
\hline Amrutha et al. & 2017 & Índia & $\begin{array}{l}\text { Ácido acético, } \\
\text { ácido lático e } \\
\text { ácido cítrico }\end{array}$ & $\begin{array}{l}\text { Frutas e vegetais } \\
\text { frescos }\end{array}$ & $\begin{array}{l}\text { Os ácidos orgânicos podem atuar como } \\
\text { sanitizantes potenciais eficazes na } \\
\text { redução da carga microbiana associada } \\
\text { a frutas e vegetais frescos. }\end{array}$ \\
\hline José et al. & 2018 & Brasil & Ácido lático & Tomate cereja & $\begin{array}{l}\text { O tratamento com ácido lático foi tão } \\
\text { eficaz quanto o uso do cloro na redução } \\
\text { de microorganismos dos tomates. }\end{array}$ \\
\hline
\end{tabular}


No mesmo ano, a pesquisa de Akbas e Ölmez (2007) realizou experimento parecido onde abordou a eficácia de diferentes ácidos orgânicos (ácido acético, lático e cítrico) na desinfecção de E. Coli e L. monocytogenes em alfaces frescas. Sua metodologia foi semelhante às mencionadas e sua amostra consistiu em porções de $25 \mathrm{~g}$ de alfaces previamente lavadas e selecionadas em folhas intactas e não murchas.

Segundo Akbas e Ölmez (2007), em comparação com L. monocytogenes, a E. coli foi mais sensível ao efeito dos ácidos orgânicos e a resistência desta primeira pode estar relacionada a alguma propriedade inerente do próprio organismo. Ele também afirma que a imersão de alface em ácidos orgânicos com concentração de mais de $1 \%$ pode influenciar a qualidade organoléptica das amostras. Portanto, é importante alcançar o grau máximo de redução na população microbiana em menor concentração de ácidos orgânicos em um período de tempo mais curto.

Uma análise mais complexa foi realizada por Park et al. (2011) ao observar a ação de variados ácidos orgânicos na redução de L. monocytogenes, E. Coli e Salmonella Typhimurium presentes em maçãs orgânicas frescas e alface. As amostras inoculadas foram imersas em soluções de $1 \mathrm{~L}$ à $1 \%$ ou $2 \%$ de cada ácido orgânico por $0.5,1.5$ e $10 \mathrm{~min}$ e à temperatura ambiente $(22 \pm 2 \circ \mathrm{C})$. Tratando-se do ácido acético foi visto que sua atividade sanitizante após $0.5 \mathrm{~min}$ à $2 \%$ reduziu nas maçãs e na alface, respectivamente, $0.52 \mathrm{logs} / \mathrm{maçã} \mathrm{e} 0.63 \mathrm{logs} / \mathrm{g}$ de E.coli; $1.12 \mathrm{logs} / \mathrm{maçã} \mathrm{e} 1.01 \mathrm{logs} / \mathrm{g}$ de S. Typhimurium.

$\mathrm{Em} 5 \mathrm{~min}$ à $1 \%$ reduziu $2.10 \log$ /maçã de $L$. monocytogenes. A maior redução ocasionada pelo ácido acético nesse estudo foi em $5 \mathrm{~min}$ à $1 \%$ e $2 \%$ na alface, eliminando 0.96 e $1.69 \mathrm{logs} / \mathrm{g}$ de L. monocytogenes, respectivamente. Segundo Park et al. (2011), a eficácia dos ácidos orgânicos em descontaminar o patógeno alimentar foi semelhante ou superior àquela dos sanitizantes à base de cloro avaliados em outros estudos. Para fins comparativos, populações de L. monocytogenes em alface foram reduzidas (1.7logs/ g) quando tratadas com 100ppm de água clorada por $5 \mathrm{~min}$ (Akbas \& Olmez, 2007).

\section{2 Ácido Lático ou Ácido Láctico (C3H6O3)}

A pesquisa realizada por Zhang e Farber (1996) também evidenciou a atividade do ácido lático sobre a $L$. monocytogenes, onde em uma concentração de $1 \%, 0$ ácido lático reduziu em $10 \mathrm{~min}$ cerca de 5 logs da bactéria. É importante comentar sobre a ação desse ácido em conjunto ao cloro, que obteve maior eficácia na redução dos níveis de $L$. monocytogenes quando comparado às suas ações isoladas. 
O estudo de Akbas e Ölmez (2007) também utilizou o ácido lático como um de seus agentes sanitizantes e avaliou a ação desse ácido sobre a alface inoculada com $L$. monocytogenes e Escherichia Coli, separadamente. A eficácia da ação do ácido lático descontaminando a hortaliça durante um período de $2 \mathrm{~min}$ foi observada. Com uma concentração de $0.5 \%$ de ácido ático, a solução foi capaz de reduzir 9 logs de $E$. Coli e 5 logs de L. monocytogenes.

Outros ácidos, maiores concentrações e tempos mais longos foram testados no experimento, contudo a máxima redução das bactérias em questão ocorreu quando submetidas à tratamento com ácido lático em concentração de $0.5 \%$ por $2 \mathrm{~min}$. De acordo com os autores, esse resultado pode ser explicado pela própria natureza da bactéria, à aderência no tecido do alimento e até mesmo ao $\mathrm{pH}$ das soluções que podem favorecer ou não a atividade dos sanitizantes.

Em outra pesquisa, realizada por Martínez-téllez et al. (2009), foi observado um efeito significativo na concentração de ácido lático para eficácia da higienização de cebolas e aspargos verdes frescos. A parte inicial do seu método foi semelhante à maioria já citadas, porém existiu um diferencial quanto à aplicação do sanitizante. $\mathrm{Na}$ maioria dos experimentos a aplicação se dava por remolho ou até mesmo por imersão, neste estudo foi realizado um processo que consiste em uma aplicação por pulverização das soluções com desinfetantes a $10^{\circ} \mathrm{C}$ durante 40,60 e $90 \mathrm{~s}$. A ação sanitizante do ácido lático neste estudo mostrou-se mais eficaz quando em concentrações maiores (2\%), onde houve inibição de Salmonella sp., a bactéria inoculada, em $2.9 \mathrm{logs} / \mathrm{g}$. Os autores comparam a eficácia do ácido lático com a do hipoclorito de sódio na sanitização, observando que este primeiro mostrou uma inibição mais eficaz em aspargos frescos inoculados com a bactéria.

Park et al. (2011), em seus experimentos também utilizaram o ácido lático como sanitizante a fim de avaliar sua eficácia sobre três patógenos diferentes. Maçãs contaminadas com E. Coli obtiveram redução de 0.71 logs/maçã após tratamento com $2 \%$ de ácido lático durante $0.5 \mathrm{~min}$ e mais de $2.56 \mathrm{logs} /$ maçã foram reduzidos com a mesma concentração do ácido após $10 \mathrm{~min}$, em comparação com o tratamento de controle. $\mathrm{O}$ segundo patógeno foi a $S$. Typhimurium, que foi reduzida 1.69logs/maçã após tratamento com $1 \%$ de ácido lático durante $0.5 \mathrm{~min}$. Após $5 \mathrm{~min}$ houveram reduções significativas do terceiro patógeno, L. monocytogenes, que foi reduzida em 1.19logs/maçã com a concentração de $1 \%$ de ácido lático.

Um estudo feito por Massey et al. (2013), utilizou diferentes ácidos orgânicos e extrato vegetal para tratamento de melões, cortados em cubos. Esta pesquisa traz a mesma 
base metodológica que as demais já mencionadas e é a segunda em que a aplicação do sanitizante se dá por meio de pulverização. Neste caso os melões em cubos previamente inoculados com E. Coli, são submetidos à jatos de spray duas vezes durante 5 s e em seguida são armazenados em sacos plásticos à $4^{\circ} \mathrm{C}$ por 12 dias para determinar a eficácia dos antimicrobianos.

Se tratando de ácidos orgânicos, Massey et al. (2013) uniu o ácido lático com ácido málico para observar a atividade sanitizante quando em conjunto e também individualmente de cada um deles. O ácido lático na concentração de $2 \%$ foi capaz de demonstrar redução de E. coli de $0.6 \mathrm{log} / \mathrm{g}$ após 3 dias de armazenamento. Ácido lático e málico em combinação na concentração de $2 \%$ apresentou redução adicional à medida que o período de armazenamento progrediu. No $12^{\circ}$ dia de armazenamento, reduziu o patógeno nos cubos de melão em aproximadamente $2.0 \mathrm{logs} / \mathrm{g}$. Essa redução se dá devido aos ácidos orgânicos possuírem efeitos antimicrobianos pela capacidade de penetrar na membrana celular e diminuir o $\mathrm{pH}$ intracelular.

José et al. (2018) publicou um artigo evidenciando grande eficácia do ácido lático na sanitização de vegetais. Neste experimento eles trataram tomates cereja inoculados com bolores e leveduras sob a ação de diferentes sanitizantes, sendo o ácido lático em uma concentração de $1 \%$ por $5 \min$ a $7^{\circ} \mathrm{C}$. Verificou-se então que quando combinado a nanoparticulas de prata e ultrassom, compondo tratamentos mistos, obtinha-se o resultado mais eficaz de sua pesquisa.

Estas combinações promoveram reduções estatisticamente iguais ao dicloroisocianurato de sódio ( $p>0,05)$, por exemplo e, de acordo com os autores, esse resultado indica que os tratamentos realizados tiveram efeitos semelhantes na redução da contagem de bolores e leveduras. Vale salientar que no ano anterior José (2017) publicou um artigo de revisão que já confirmava essa atividade sanitizante do ácido lático como uma estratégia alternativa de descontaminação de alimentos. Segundo ela, os ácidos lático, acético e cítrico têm capacidade de inibir o crescimento de E. coli, Listeria monocytogenes e Salmonella spp. em produtos frescos. É citado em sua revisão o estudo de Huang e Chen (2011), evidenciando que o uso de ácido lático a 1\% foi o mais eficiente promovendo uma redução de $1.9 \operatorname{logs} / g$ de E. coli em espinafres.

\section{3 Ácido Cítrico ou Citrato de Hidrogênio (C6H8O7)}

Akbas e Ölmez (2007) enriqueceu seu estudo evidenciando também a atividade do 
ácido cítrico na desinfecção de hortaliças. A eficácia da ação desse ácido descontaminando a alface com concentração de $0,5 \%$ durante um período de 2 a 5 min foi observada. Contatou-se uma capacidade de diminuição de $0,2 \operatorname{logs}$ de $E$. Coli e $0,9 \operatorname{logs}$ de $L$. monocytogenes. Segundo os autores, a atividade do ácido cítrico mostrou-se eficaz tão quanto à do ácido lático e que diferentes concentrações do ácido tratando as amostras em diferentes intervalos de tempo não interferem tanto em sua efetividade enquanto agente sanitizante.

Para Park et al. (2011), a atividade do ácido cítrico durante todo o experimento foi muito semelhante àquela exercida pelo ácido lático. Este ácido resultou em diminuições dos níveis inoculados de bactéria nos intervalos de tempo e concentrações estipulados. Seu efeito sobre a $E$. Coli se deu já na metade do primeiro minuto da experiência, quando maçãs e alfaces imersas em solução à $1 \%$ e $2 \%$ de ácido cítrico evidenciaram diminuição de 0.58 e $0.78 \operatorname{logs}$ da bactéria, respectivamente. Em $1.5 \mathrm{~min}$ de imersão à $2 \%$, maçãs e alfaces obtiveram um resultado relevante de 1.51 e 1.34logs de E. Coli reduzidos. Após 10 min de imersão a atividade do ácido cítrico à $2 \%$ foi capaz de reduzir mais de $2.56 \mathrm{logs} /$ maçã, à $1 \%$ e $2 \%$ diminuiu 2.25 e $2.86 \mathrm{logs} / \mathrm{g}$ de alface, respectivamente. Sua atividade sobre a $S$. typhimurium na maçã e na alface à $1 \%$ em $0.5 \mathrm{~min}$ foi capaz de reduzir 1.23 e 0.89 logs de bactéria e à $2 \%$ reduziu 1.99 e 1.14 logs, respectivamente. Maior eficácia do ácido cítrico foi observada após $10 \mathrm{~min}$ em uma concentração de $2 \%$ sobre a maçã, que reduziu 3.42logs dessa bactéria. Os resultados mais relevantes sobre a ação antiparasitária do ácido cítrico sobre a L. monocytogenes foi com a utilização da solução por $10 \mathrm{~min}$ à $1 \mathrm{e}$ $2 \%$ na alface e na maçã resultando, respectivamente, na diminuição de 1.18 e 2.90 logs de bactéria. Park et al. (2011), afirmam que entre os ácidos orgânicos testados em seu experimento, o ácido cítrico foi um dos ácidos orgânicos que apresentaram maior redução dos níveis microbianos, tanto na maçã quanto na alface.

Um estudo mais recente realizado por Akbas e Cag (2016) utilizou-se de uma metodologia diferenciada que também avaliou a atividade sanitizante do ácido cítrico, mas agora sobre seu efeito redutor de Bacillus subtilis. A pesquisa não traz a amostra como alimento inoculado, mas sim placas de ensaio cultivadas com cepas da bactéria e posteriormente submetidas à exposição de diferentes sanitizantes como o hipoclorito de sódio e o ácido cítrico. Os principais resultados deste estudo trouxeram pontos positivos sobre o efeito antiparasitário do ácido cítrico. A prevenção de formações de biofilme estava na faixa de $89 \%$ a $91 \%(p<0,05)$ quando tratamentos com ácido cítrico a $1 \%$ foram usados antes da formação da biofilme e permaneceu em $91 \%(p>0,05)$ com tratamentos com ácido 
cítrico a 2\% após 24, 48 e 72 horas. Dados semelhantes à atividade do cloro que em 24 hrs a 100ppm de solução preveniu de 92 a $95 \%(p<0,05)$ a formação de biofilme.

Tais resultados são confirmados em uma pesquisa mais recente realizada por Amrutha, Sundar e Shetty (2017) onde mesclou a metodologia mais comum avaliando a descontaminação da superfície do pepino e também a redução da proliferação em placas de biofilme inoculadas com patógeno específico de E. Coli e Salmonella sp. Em seu estudo avaliou os três ácidos orgânicos mais estudados nesta revisão, o ácido acético, cítrico e lático. Os resultados mais significativos deste experimento estão relacionados à inibição máxima da formação de biofilme registrada em uma máxima de $39.13 \%$ com ácido láctico em E. coli e um mínimo de $22.53 \%$ com ácido cítrico em Salmonella sp, evidenciando a efetividade do ácido cítrico e a eficácia do ácido lático.

\section{CONCLUSÃO}

Os ácidos orgânicos devem receber uma maior atenção como alvo de pesquisas e estudos que busquem evidências para adequá-los como alternativa natural e eficaz para controle microbiano de alimentos consumidos in natura ou minimamente processados, havendo assim a possibilidade de reduzir o uso de sanitizantes químicos pelas indústrias alimentícias.

A eficácia e efetividade de diferentes ácidos orgânicos serão diretamente relacionadas à sua natureza, concentração e tempo de tratamento. Alterações específicas como mudança de $\mathrm{pH}$ e oscilação de temperatura do ambiente durante o experimento também influenciam diretamente na atividade sanitizante.

Apesar de possuírem potencial semelhante ao de outros sanitizantes químicos usados para desinfecção do alimento, os ácidos orgânicos ainda não fornecem os requisitos necessários para serem utilizados isoladamente como uma alternativa de sanitização de alimentos. Além disso, a Agencia Nacional de Vigilância Sanitária (ANVISA) ainda não reconhece os ácidos orgânicos como sanitizantes de alimentos, o que torna irregular seu uso para este fim.

Sugere-se ainda a realização de estudos que possam demonstrar a relação custobenefício dos ácidos orgânicos com os sanitizantes químicos comumente utilizados, além de mais estudos que avaliem a eficácia da ação sanitizante dos ácidos orgânicos sobre todos os possíveis microorganismos causadores de DTAs geralmente encontrados nos alimentos. 


\title{
5 AGRADECIMENTOS
}

À Universidade Estadual do Ceará (UECE).

\section{REFERÊNCIAS}

\begin{abstract}
ABRANCHES, M. V. Introdução á qualidade sanitária em unidades de alimentação e nutrição: conheça os conceitos que regem o setor de alimentação coletiva e entenda os principais pontos de cadeia produtiva de refeições. Viçosa: A.S.Sistemas. Leseprobe, 2015.
\end{abstract}

AKBAS, M. Y.; CAG, S. Use of organic acids for prevention and removal of Bacillus subtilis biofilms on food contact surfaces. Food Science and Technology International, v. 22, n.7, p.587-597, 2016. https://doi.org/10.1177/1082013216633545.

AKBAS, M. Y.; ÖLMEZ, H. (2007). Inactivation of Escherichia coli and Listeria monocytogenes on iceberg lettuce by dip wash treatments with organic acids. Letters In Applied Microbiology, v. 44, n.6, p. 619-624, 2007. https://doi.org/10.1111/j.1472-765X.2007.02127.x.

ALEGBELEYE, O. O.; SINGLETON, I.; SANT'ANA, A. S. Sources and contamination routes of microbial pathogens to fresh produce during field cultivation: a review. Food microbiology, v.73, p. 177-208, 2018. https://doi.org/10.1016/.fm.2018.01.003.

AMRUTHA, B.; SUNDAR, K.; SHETTY, P. H. Effect of organic acids on biofilm formation and quorum signaling of pathogens from fresh fruits and vegetables. Microbial Pathogenesis, v.111, p.156-162, 2017. http://dx.doi.org/10.1016/j.micpath.2017.08.042.

BERMÚDEZ-AGUIRRE, D.; BARBOSA-CÁNOVAS, G.V. Disinfection of selected vegetables under nonthermal treatments: Chlorine, acid citric, ultraviolet light and ozone. Food Control, v.29, n.1, p.82-90, 2013. http://dx.doi.org/10.1016/j.foodcont.2012.05.073.

CHANG, J. M.; FANG, T. J. Survival of Escherichia coli O157: H7 and Salmonella enterica serovars Typhimurium in iceberg lettuce and the antimicrobial effect of rice vinegar against $\mathrm{E}$. coli O157. Food Microbiology, v. 24, n.7-8, p.745-751, 2007.

http://dx.doi.org/10.1016/i.fm.2007.03.005.

CASTRO-IBÁÑNEZ, I.; GIL, M.I.; ALLENDE, A. Ready-to-eat vegetables: Current problems and potential solutions to reduce microbial risk in the production chain. LWT-food Science and Technology, v.85, p.284-292, 2017. http://dx.doi.org/10.1016/j.Iwt.2016.11.073.

COELHO, C. C. S.; FREITAS-SILVA, O.; CAMPOS, R. S.; BEZERRA, V. S.; CABRAL, L. M. C. Ozonização como tecnologia pós-colheita na conservação de frutas e hortaliças: Uma revisão.

Revista Brasileira de Engenharia Agrícola e Ambiental, v.19, n.4, p.369-375, 2015. https://doi.org/10.1590/1807-1929/agriambi.v19n4p369-375.

FERNANDES, G. R. Sanitizantes alternativos na qualidade microbiológica, física e química de morangos (Fragaria x Ananassa Duch) minimamente processados. Tese (Doutorado) Universidade Federal de Viçosa, Minas Gerais, MG. 2013.

HUANG, Y. \& CHEN, H. Effect of organic acids, hydrogen peroxide and mild heat on inactivation of Escherichia coli O157: H7 on baby spinach. Food Control, v. 22, n.8, p.1178-1183, 2011. https://doi.org/10.1016/i.foodcont.2011.01.012. 
JOSÉ, J. F. B., MEDEIROS, H. S., ANDRADE, N. J. \& VANETTI, M. C. D. (2018). Effect of ultrasound and chemical compounds on microbial contamination, physicochemical parameters and bioactive compounds of cherry tomatoes. Italian Journal of Food Science, v.30, n.3, p.467-486. http://dx.doi.org/10.14674/IJFS-1015.

JOSÉ, J. F. B. (2017). Estratégias alternativas na higienização de frutas e hortaliças. Revista de Ciências Agrárias, v.40, n.3, p.630-640. http://dx.doi.org/10.19084/RCA16124.

MARTÍNEZ-TÉLLEZ, M. A.,;RODRIGUEZ-LEYVA, F. J.; ESPINOZA-MEDINA, I. E. ; VARGASARISPURO, I. Sanitation of fresh green asparagus and green onions inoculated with Salmonella. Czech Journal of Food Sciences, v.27, n.6, p.454-462, 2009. http://dx.doi.org/10.17221/138/2008-CJFS.

MASSEY, L. M.; HETTIARACHCHY, N. S.; MARTIN, E. M.; RICKE, S. C. Electrostatic Spray of Food-Grade Organic Acids and Plant Extract to Reduce Escherichia coli O157:H7 on Fresh-Cut Cantaloupe Cubes. Journal of Food Safety, v.33, n.1, p.71-78, 2013. https://doi.org/10.1111/jfs.12024.

MEDEIROS, L.; DALL'AGNOL, L. P.; BOTTON, S. A.; SMANIOTTO, H.; POTTER, R.; CAMPOS, M. M. A.; MATTOS, K. M.; LOPES, L. F. D.; SANGIONII, L. A. Qualidade higiênico-sanitária dos restaurantes cadastrados na Vigilância Sanitária de Santa Maria, RS, Brasil, no período de 2006 a 2010. Ciência Rural, v.43, n.1, p.81-86, 2013. https://doi.org/10.1590/S010384782012005000146.

MEIRELES, Ana; GIAOURIS, Efstathios; SIMÕES, Manuel. Alternative disinfection methods to chlorine for use in the fresh-cut industry. Food Research International, v. 82, p. 71-85, 2016. https://doi.org/10.1016/..foodres.2016.01.021.

MENDES, K. S.; SILVEIRA, R. C. C. P.; GALVÃO, C. M. Revisão integrativa: método de pesquisa para a incorporação de evidências na saúde e na enfermagem. Texto Contexto Enferm, v.17, n.4, p.758-764, 2008. https://doi.org/10.1590/S0104-07072008000400018.

NASCIMENTO, E. D.; ALENCAR, F. L. S. Eficiência antimicrobiana e antiparasitária de desinfetantes na higienização de hortaliças na cidade de Natal - RN. Ciência e Natura, v. 36, n.2, p.94-106, 2014. http://dx.doi.org/10.5902/2179460X12755.

ÖLMEZ, H.; KRETZSCHMAR, U. Potential alternative disinfection methods for organic fresh-cut industry for minimizing water consumption and environmental impact. LWT-Food Science and Technology, v.42, n.3, p.686-693, 2009. http://dx.doi.org/10.1016/j.Iwt.2008.08.001.

Park, S. H.; Choi, M. R.; Park, J. W.; Chung, M. S.; Ryu, S.; Kang, D. H. Use of Organic Acids to Inactivate Escherichia coli O157:H7, Salmonella Typhimurium, and Listeria monocytogenes on Organic Fresh Apples and Lettuce. Journal of Food Science, v.76, n.6, p.293-298, 2011. http://dx.doi.org/10.1111/j.1750-3841.2011.02205.x.

RODRIGUES, E. C. N.; RIBEIRO, S. C. A.; SILVA, F. L. Não padronização de procedimentos operacionais em agroindústria familiar de polpa de frutas e seus efeitos na renda e satisfação dos associados. Revista eumednet, v.208, n.11, p.1-19, 2015.

TAKAYANAGUI, O. M.; OLIVEIRA, C. D.; BERGAMINI, A. M. M.; CAPUANO, D. M.; OKINO, M. H. T.; FEBRÔNIO, L. H. P.; SILVA, A. A. M. C. C.; OLIVEIRA, M. A.; RIBEIRO, E. G. A.;

TAKAYANAGUI, A.M. M. Fiscalização de verduras comercializadas no município de Ribeirão

Preto, SP. Revista da Sociedade Brasileira de Medicina Tropical, v. 34, n.1, p.37-41, 2001. 
YAMAGUCHI, M. U.; ZANQUETA, E. B.; MOARAIS, J. F.; FRAUSTO, H. S. G.; SILVÉRIO, H. I. Qualidade microbiológica de alimentos e de ambientes de trabalho: Pesquisa de Salmonella e Listeria. Revista em Agronegócios e Meio Ambiente, v. 6, n. 3, p. 417-434, 2013.

ZHANG, S.; FARBER, J. M. The effects of various disinfectants against Listeria monocytogenes on fresh-cut vegetables. Food Microbiology, v.13, n. 4, p.311-321. 1996. 